\title{
OPTIMIZATION OF THE SALES FLOW OF DAIRY PRODUCTS AT RETAIL
}

\section{${ }^{1}$ Eduardo Jose Borges Caldeira Rodrigues Alves, ${ }^{1}$ Mauro Cezar Aparício de Souza, ${ }^{1}$ Alexandra Priscilla Tregue Costa, ${ }^{2}$ Marden Eufrasio dos Santos and ${ }^{2,}$ David Barbosa de Alencar}

${ }^{1}$ Academic department, University Center FAMETRO, Amazon-Brazil

2Institute of Technology and Education Galileo of Amazon (ITEGAM), Brazil

\section{ARTICLE INFO}

Article History:

Received $28^{\text {th }}$ February, 2020

Received in revised form

$16^{\text {th }}$ March, 2020

Accepted 03 ${ }^{\text {rd }}$ April, 2020

Published online $30^{\text {th }}$ May, 2020

Key Words:

Ishikawa Diagram, Pareto diagram,

5W2H, Process Flow Mapping, Sales.

\begin{abstract}
The work presents a study that aims to analyze certain products in a company in the commercial branch of dairy products of animal origin. Analyzes will be carried out on the sliced cheese products, the butter jar and the chocolate drink, as they present more critical problems in relation to the recipe. Through the analysis of these products, there will be a demonstration of results in the verification of their quality. To make a study with better sales rates, we will use some tools used in the classroom. The quality tools, Ishikawa diagram, Pareto diagram and $5 \mathrm{~W}$ will be used, as they will determine the causes of the problem of the low revenue of these products. In addition, process flow mapping will be used to describe how the sales sector approach is effect. With this, the study seeks to present a proposal for improvement in increasing the percentage of revenue of this company and the popularization of these certain products in the market, in addition to bonus its employees through the fulfillment of goals that will be established.
\end{abstract}

*Corresponding author:

David Barbosa de Alencar

Copyright (C) 2020, Eduardo Jose Borges Caldeira Rodrigues Alves et al. This is an open access article distributed under the Creative Commons Attribution License, which permits unrestricted use, distribution, and reproduction in any medium, provided the original work is properly cited.

Citation: Eduardo Jose Borges Caldeira Rodrigues Alves, Mauro Cezar Aparício de Souza, Alexandra Priscilla Tregue Costa, Marden Eufrasio dos Santos and David Barbosa de Alencar. "Optimization of the sales flow of dairy products at retail”, International Journal of Development Research, 10, (05), 35967-35971.

\section{INTRODUCTION}

O trabalho apresenta três etapas para análise da otimização do fluxo de vendas de produtos no varejo, o mesmo iniciará com o mapeamento do fluxo de processos, utilização das ferramentas de qualidade, diagrama de Ishikawa, diagrama de Pareto e $5 \mathrm{~W}$, para identificar das principais causas do problema e posteriormente a implementação das ações propostas. Dessa forma, propondo ações para aumentar a receita dos três produtos mais críticos de uma empresa de varejo, já que dessa forma gera oportunidades de melhoria no fluxo de venda de produtos, o que contribui para melhorar o desempenho das vendas no varejo. O fluxo de vendas é usado por algumas empresas para atrair, criar interesses na sua marca, gerar curiosidade sobre o mercado concorrente e negociar vendas com seus clientes. O mesmo será analisado com o aumento da visibilidade da marca, havendo o acompanhamento dos vendedores para seus produtos, parcerias com os clientes atuais, obtenção de um relacionamento de mais confiança com os antigos clientes e uma forma melhor de negociação com os mesmos.
O sucesso de um varejista (retalhista), seja este pequeno ou grande porte, depende principalmente do quanto ele incorpora o conceito de venda ao consumidor. Este conceito é uma orientação de gestão que faz o varejista focar nas necessidades do seu mercado-alvo, e como será mais eficaz e eficiente que os seus concorrentes, conforme (TORRELLA; SOUZA,2004). $\mathrm{Na}$ parte de lacticínios demonstrará o armazenamento, sua venda e sua revenda final, e posteriormente ter um crescimento no ramo empresarial, obtendo um lucro maior e a realização maior de divulgação da marca. Este estudo tem ainda uma contribuição social, apresentando um potencial de ganho para os colaboradores da empresa envolvida. Essa organização bonifica seus funcionários através do cumprimento de metas. Uma das principais metas está relacionada com a venda dos três produtos mais críticos. Com a redução das causas encontradas, haverá um aumento da receita, gerando um ganho para os colaboradores.

\section{FUNDAMENTAÇÃO TEÓRICA}

Logística: Conforme (ARBACHE, 2011) a logística é importante porque é capaz de auxiliar empresas e organizações 
na agregação e criação de valor ao cliente. Ela pode ser a chave para uma estratégica empresarial de sucesso, provendo uma multiplicidade de maneiras para diferenciar a empresa da concorrência através de um serviço superior ou, ainda, por meio de interessantes reduções de custo operacional. De acordo com o CouncilofLogistics Management (CLM): "Logística é o processo de planejamento, implantação e controle do fluxo eficiente e eficaz de mercadorias, serviços e das informações relativas desde o ponto de origem até o ponto de consumo com o propósito de atender às exigências dos clientes" (Ballou, 2006). Alguns autores citam o conceito de logística como apenas transporte ou o estoque/armazenagem de produtos, no entanto, a logística engloba o transporte, o estoque/armazenagem de produtos e diversas outras atividades que envolvem o processo, desde o fornecimento para a produção até a entrega do produto final ao cliente. Através da logística, o comércio no varejo tem várias concepções de pontos de vista, mas a essência principal do conceito de varejo, decorre da realização de vendas no comércio para consumidores finais, atendendo qualquer tipo de cliente e chegando a obter clientes em nível domiciliar através de um bom planejamento da logística. O modo de varejo pode ser realizado em pequenos, médios e grandes portes.

Empresa de varejo: O varejo é subdividido em setores que podem oferecer diversos serviços com o envolvimento de maior parceria entre $o$ fornecedor, vendedor e o estabelecimento comercial. Para Aulowidi e Keller (2004, p.332) o varejo identifica os bens e serviços de um varejista e os diferentes modos de formas de competição comercial, a parte da colocação de lucros dependentes de como a concepção de aceitação do consumidor final. A oferta é a forma de comunicação até a chegada no fim do processo, é uma cadeia de porte constituída por conjunção, valores e confiabilidade, pois há produtos que serão colocados em testes para o aumento da proteção e divulgação da marca. $\mathrm{O}$ novo método de vendas no varejo não tem somente a concorrência com outras marcas, mas sim, o novo rumo dos atacarejos, ou seja, quem vende todos os tipos de mercadorias, com preços mais acessíveis que os seus. $O$ varejo necessita de procedimentos atrativos para ser elaborado o novo modelo de comércio de alimentos, para ser mais viável o controle no objetivo de vendas e em busca de resultados positivos. $\mathrm{O}$ comércio de produtos perecíveis necessita de um tratamento personalizado, como por exemplo a comercialização de dois produtos da empresa em questão, que são os queijos fatiados e o pote de manteiga. Onde o pote de manteiga necessita de um armazenamento em ambiente de temperatura dentro das normas dos órgãos fiscalizadores, assim como os queijos fatiados.

Mapeamento do fluxo de valor: O esforço de se manter e reduzir desperdícios ou perdas, surge novas características nos empreendedores, como o conceito de agregação de valores, onde são separadas partes que geram lucros, daquelas que geram desperdícios ou prejuízos aos seus processos. O mapa de valor tem o objetivo de demonstrar a capacidade de formar um conjunto de ações para ter uma avaliação mais complexas das marcações e das partes numéricas de suas medições e de formatar uma ideia mais coerente na sua agregação de problema. Para Rother e Shook (2012.p1), o fluxo é uma ação que agregar valor ou não, é não separando produtos ou de processos, o fluxo traz toda a essência de ambos, o mesmo vem trazendo para o rumo comercial sua visão desde do produtor que faz a matéria prima, passando pelo ramo da industrialização do material e chegando na parte final que é sua comercialização aos clientes. O MFV é a forma mais abrangente nos meios das novas técnicas aplicadas no meio da formalização de mapeamento. Alguns autores formalizam suas ideias de que o próprio faz sua concepção de simbologia de demarcação, introduzindo suas características para o ramo comercial, e formalizando o objetivo de organizar e determinar suas características de vendas ao consumidor final, além de mostrar sua organização de características de metas dos vendedores. A clareza do mapa faz ele ter uma maior capacitação de obter dados com mais qualidades dos processos e fazer que a visualização obtenha um melhor entendimento na análise numérica da parte de que tem a missão de verificar os números e acompanhar os demonstrativos das metas dos seus colaboradores. O processo de mapeamento do fluxo não está somente ligado a parte industrial em linhas manufaturadas, porém cria benefícios para outras áreas de atuação, como por exemplo a área de comercialização de produtos. Conforme Jones e Wanack (2004), o mapeamento do fluxo de valor tem a capacidade analítica dos processos e os mesmos que denominam o fluxo estendido em sua concepção de análise da parte de projetos.

\section{Ferramentas da qualidade}

Diagrama de Ishikawa: Utilizando a ferramenta de qualidade, diagrama de Ishikawa, é possível realizar uma análise das causas e efeito da problemática e posteriormente verificar as possíveis implementações das correções, de acordo com a análise do diagrama. A ferramenta de qualidade, diagrama de Ishikawa, irá coletar a problemática do processo de vendas desse estudo de caso, e apresentará as principais causas e efeito, com a característica de evoluir para a realização da correção da problemática levantada. Conforme (Faiconi,1989), o diagrama permite analisar o problema por índice de hierarquicamente, podendo determinar suas causas e efeito, e provar claramente uma projeção de uma solução mais viável e mais rentável. O Diagrama de Ishikawa é uma ferramenta que se utiliza para descrever uma ligação entre a consequência de um processo (efeito) e os motivos (causa) do processo. Também chamado de diagrama de espinha de peixe, na qual mostra as principais causas de determinadas atividades, em que apontam para subcausas, encaminhando-se para um resultado final (CÉSAR, 2011, p.63). "O diagrama de causa e efeito foi desenvolvido para representar as relações existentes entre um problema ou efeito indesejável do resultado de um processo e todas as possíveis causas desse problema, atuando como um guia para a identificação da causa fundamental deste problema e para a determinação das medidas corretivas que deverão ser adotadas" (CARPINETTI, 2012, p. 83).

Diagrama de Pareto: Carpinetti (2012) declara que o princípio de Pareto afirma que algumas poucas causas, entre todas, são responsáveis pelos efeitos indesejáveis desse problema. Assim, se forem encontradas as principais causas de um problema, será possível resolver quase todas as perdas por meio de poucas ações. Confome citado por Vieira (1999), é uma ferramenta que estabelece a ordem em que as causas das perdas devem ser sanadas, sendo esse o foco na área da qualidade. Segundo RAMOS (2000: 100), “O diagrama de Pareto é usado quando é preciso dar atenção aos problemas de uma maneira sistemática e quando se tem um grande número de problemas e recursos limitados para resolvê-los". Como o objetivo desse trabalho é identificar e propor ações de melhoria para os produtos: queijo fatiado, manteiga em pote e 
achocolatado, essa ferramenta se encaixa perfeitamente para alcançar o objetivo do estudo. Através de seu uso, será possível ordenar a desconformidade desses produtos com o programado para a venda, e agir contra elas. Além disso, o diagrama de Pareto é uma ferramenta simples, visual, e que busca identificar e priorizar problemas. Assim, foi utilizado para identificar as principais causas da receita abaixo do esperado dos três produtos já citados.

5W2H: Para Daychouw (2007), a ferramenta 5W2H pode ser utilizada em várias áreas de conhecimento, ajudando sempre no planejamento, como:

- Planejamento da Qualidade - Serve para identificar determinados padrões de qualidade que são importantes para o projeto e com isso definir como atender esses padrões;

- Planejamento das Aquisições - Usado para identificar quais as reais necessidades do projeto devem ser supridas por meio da contratação de produtos ou serviços de fora da organização;

- Planejamento dos Recursos Humanos - Identificar quais pontos relevantes do projeto podem ser atendidas por meio dos Recursos Humanos disponíveis na organização;

- Planejamento de Riscos - Identificar quais os riscos o projeto deve estar atento em sua elaboração.

Este método consiste basicamente em fazer perguntas no sentido de obter as informações primordiais que servirão de apoio ao planejamento de uma forma geral. A terminologia $5 \mathrm{w} 2 \mathrm{~h}$ tem origem nos temos de língua inglesa que são What, who, why, where, when, how, howmuch, howmany. (DAYCHOUM, 2013). O 5W2H busca elaborar os planos da ação de um problema. Ele direciona a execução das tarefas de forma clara e objetiva, assegurando que a implementação será feita de forma organizada (GROSBELLI, 2014). VERAS (2016, p. 136) entende que a ferramenta é um checklist de determinadas atividades que precisam ser desenvolvidas com o máximo de clareza possível por parte dos colaboradores em um projeto. Ela mapeia as atividades, onde ficará estabelecido o que será feito, quem fará o quê, em qual período de tempo, em qual área da empresa e todos os motivos pelos quais essas atividades devem ser realizadas. O $5 \mathrm{~W}$ está sendo usado neste artigo, para propor as ações para a resolução dos problemas encontrados entre os três produtos mais críticos da empresa. Além disso, essa ferramenta ajuda na identificação das causas e na formalização das propostas a serem executadas.

Folha de verificação: Segundo VIEIRA (1999: 1), "A folha de verificação é uma planilha para o registro de dados. O uso de uma folha de verificação torna a coleta de dados rápida e automática. Toda a folha de verificação deve ter espaço onde registrar local e data da coleta dos dados".

De acordo com KUME (1993: 13), Quando for preciso coletar dados, é essencial esclarecer sua finalidade e ter valores que reflitam claramente os fatos. Além dessas premissas, em situações reais é importante que os dados sejam coletados de maneira simples e num formulário fácil de usar. Uma folha de verificação é um formulário de papel no qual os itens a serem verificados já estão impressos, de modo que os dados possam ser coletados de forma fácil e concisa.

Fluxograma: Dentre as vantagens na utilização do fluxograma, segundo Mello (2008) estão:
Permite verificar como se conectam e relacionam os componentes de um sistema, mecanizado ou não, facilitando a análise de sua eficácia; Facilita a localização das deficiências, pela fácil visualização dos passos, transportes, operações e formulários; Propicia o entendimento de qualquer alteração que se proponha nos sistemas existentes pela clara visualização das modificações introduzidas.

Brainstorming: Segundo Behr, Moro e Estabel (2008) o Brainstorming é uma ferramenta simples, realizada em grupo, para evidenciar problemas e que pode ser utilizada em qualquer situação. Meireles (2001, p.20) reforça que esta é "uma ferramenta associada à criatividade" e especifica que ela deve ser utilizada na fase de planejamento.

\section{FERRAMENTAS E MÉTODOS}

Analisando os gráficos de desempenho de venda, observou-se que os produtos, queijo fatiado, manteiga em pote e achocolatado, apresentam baixa venda em relação aos demais produtos, e estão também em desconformidade com o programado para a venda. O trabalho fundamentou-se no uso metodológico do estudo de caso, pois se caracteriza pelas investigações em que, além da pesquisa bibliográfica e/ou documental, realizou-se coleta de dados junto as pessoas. $\mathrm{O}$ indicador usado por essa empresa, baseia-se no relatório de desempenho de vendas, cujo o auxílio visual é um gráfico de Pareto. Conforme o gráfico abaixo, o mesmo apresenta os últimos 6 meses do desempenho de vendas:

\section{VENDAS DE MANTEIGA}

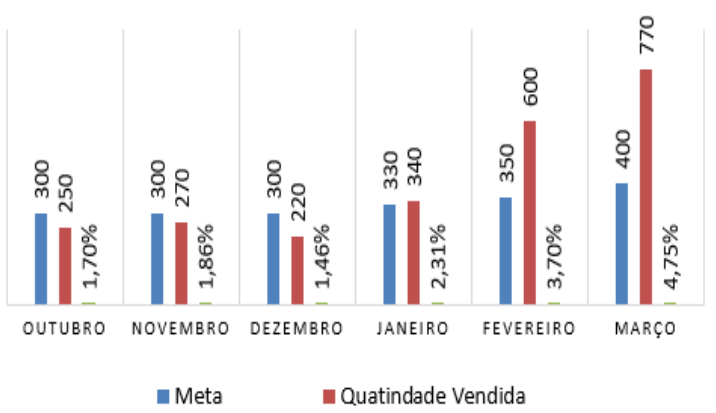

Gráfico 01. Dados do produto manteiga em pote Fonte: Os Autores, 2020.

O gráfico 1 demostra o desempenho de vendas de manteiga.

\section{VENDAS DE QUEIJO FATIADO}

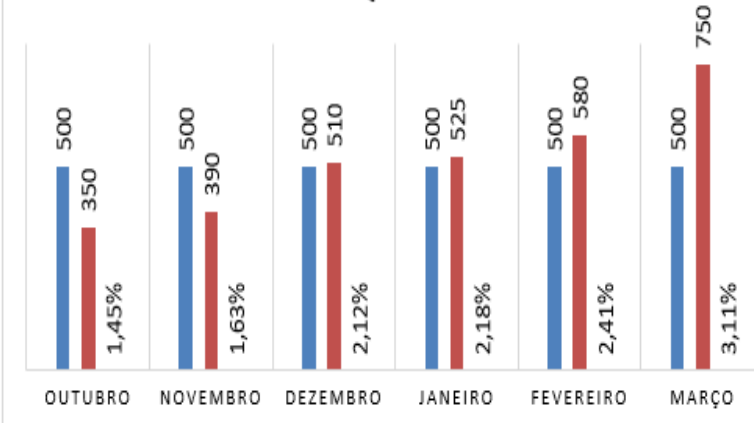

- Meta $\|$ Quantidade Vendida $=$ Porcetagem na Meta Total Fonte: Os Autores, 2020. 
O gráfico 2 demostra o desempenho de vendas de queijo fatio.

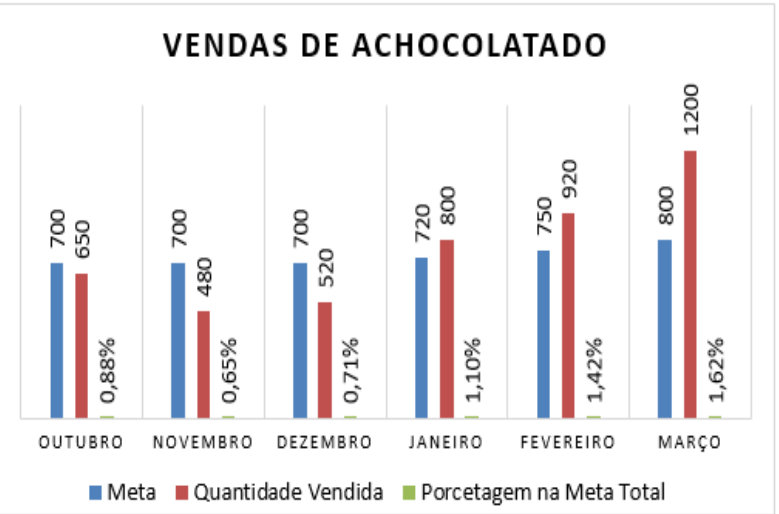

Gráfico 03. Dados do produto achocolatado Fonte: Os Autores, 2020

O gráfico 1 demostra o desempenho de vendas de achocolatado. Sendo assim, este trabalho foi realizado primeiramente por um levantamento bibliográfico, visita nos processos das vendas dos três produtos mais críticos, levantamento de informações com os colaboradores que participam do processo de venda, e posteriormente a aplicação das ferramentas, diagrama de Ishikawa, mapeamento do fluxo de processo e $5 \mathrm{~W}$.

\section{APLICAÇÃO DO ESTUDO}

A empresa em questão, apresentava em todas as suas reuniões mensais problemas críticos com três produtos, que são eles: o queijo fatiado, manteiga em pote e o achocolatado, ocasionando uma perda significativa na receita final da empresa. Dessa forma realizamos um levantamento dos problemas encontrados, através da ferramenta de qualidade, diagrama de Ishikawa, para que pudéssemos constatar os problemas a serem eliminados e assim gerar melhorias no processo das vendas desses produtos em questão. Conforme mostra a figura 1 abaixo:

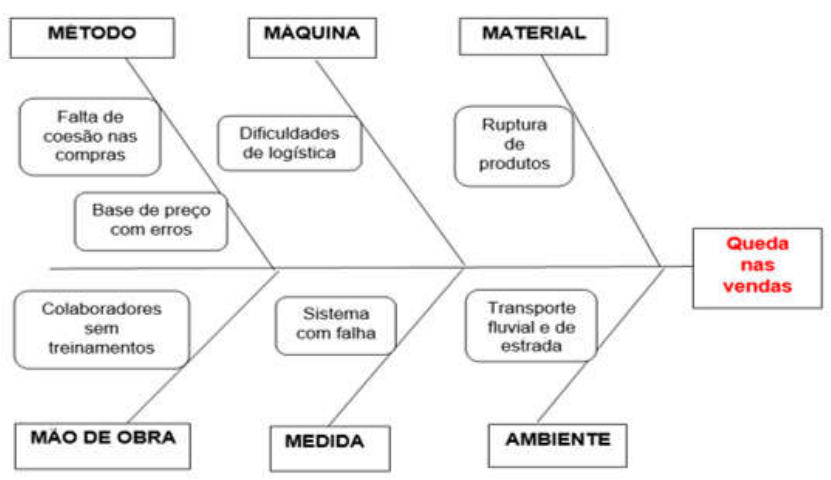

Figura 01. Diagrama Ishikawa (causa e efeito) Fonte: Os Autores, 2020.

Dessa forma, o diagrama foi desenvolvido pelos colaboradores que estavam envolvidos no processo das vendas dos três produtos mais críticos da empresa. Sendo assim, a equipe realizou sessões de brainstorming durante o mês de dezembro, com a intenção de produzir o máximo possível de ideias em um curto período de tempo. Conforme as informações mostradas na figura 1 , identificamos a causa raiz do problema, através da identificação dos $6 \mathrm{M}$.
Métodos: foi realizada uma nova negociação de valores pela quantidade de compras que serão adquiridas.

Máquinas: foi realizada a terceirização da equipe que era responsável pela entrega dos produtos. Dessa forma, obtendo pontualidade nas entregas dos produtos.

Materiais: foi realizado um novo modelo de distribuição de cargas chegando e outra carga embarcando nas fábricas.

Mão de Obra: foi realizado o treinamento com os funcionários, para que os mesmos adquirissem conhecimentos dos produtos do processo.

Medida: foi feita a troca do sistema.

Meio ambiente: mudança da logística das rotas.

Tabela 01: Aplicação da ferramenta 5W

\begin{tabular}{|c|c|c|}
\hline \multicolumn{3}{|c|}{ Problema: Dificuldade de logística } \\
\hline $5 \mathrm{~W}$ & & Ação \\
\hline What? & O que deve ser feito? & $\begin{array}{l}\text { Terceirização da equipe que era } \\
\text { responsável pela entrega dos } \\
\text { produtos }\end{array}$ \\
\hline Why? & Por que fazer? & $\begin{array}{l}\text { Para obtenção da pontualidade } \\
\text { nas entregas dos produtos. }\end{array}$ \\
\hline Who? & $\begin{array}{l}\text { Quem é o responsável } \\
\text { pela ação? }\end{array}$ & Supervisor de logística. \\
\hline Where? & $\begin{array}{l}\text { Onde deve ser } \\
\text { executado? }\end{array}$ & Dentro do setor logístico. \\
\hline When? & $\begin{array}{l}\text { Quando deve ser } \\
\text { implementado? }\end{array}$ & Até 05 de junho de 2020 . \\
\hline
\end{tabular}

Fonte: Os Autores, 2020.

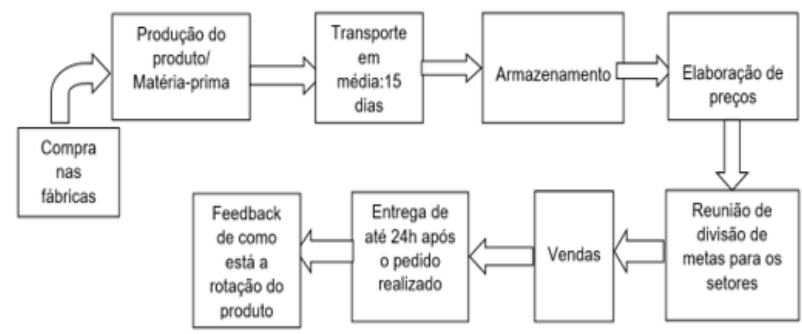

Fig. 2. Mapeamento do fluxo do processo Fonte: Os Autores, 2020

Com base nas reuniões realizadas e da construção do diagrama de Ishikawa, foi verificado que a empresa precisava realizar várias correções no processo de vendas dos três produtos mais críticos da empresa, para que os problemas nas receitas desses produtos fossem sanados. Dessa forma, foi implantada a ferramenta 5W2H, pois segundo Polacinski (2012) essa ferramenta consiste em um plano de ação para atividades préestabelecidas que tem a necessidade de serem desenvolvidas com a maior clareza possível, além de funcionar como um mapeamento dessas atividades. Já o mapeamento de processos será utilizado como padronização de qualquer tipo de documentação que compõe o processo, desde uma simples correção até análises mais complexas. Essa ferramenta tem como característica o levantamento com êxito da situação problemática. Conforme mostra a figura 2 acima, o mapeamento do fluxo de processo é necessário para identificar todas as etapas do processo, desde o recebimento da matériaprima, até a entrega do produto ao consumidor final, para que dessa forma a empresa seja analisada por completa e que nenhuma etapa passe despercebida. 


\section{RESULTADOS E DISCUSSÕES}

A partir da aplicação das ferramentas, foi evidenciado o aumento da receita dos produtos críticos no prazo de 6 meses, conforme mostra os gráficos abaixo:

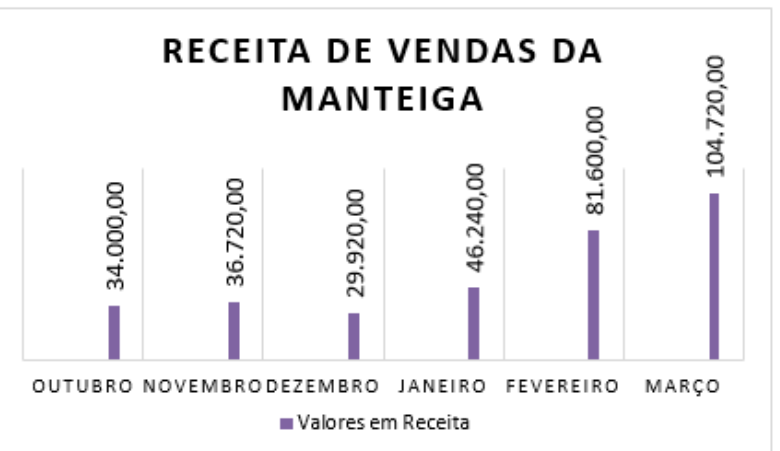

Gráfico 4. Receita do produto manteiga em pote. Fonte: Os Autores, 2020

O gráfico 4 mostra a receita das vendas da manteiga em pote.

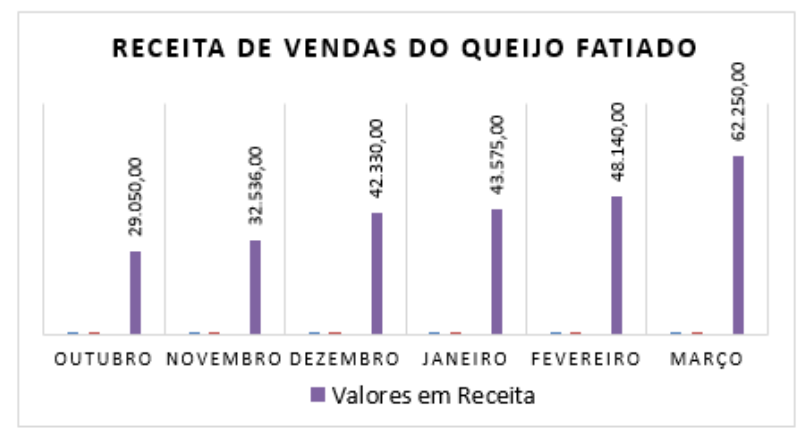

Gráfico 5. Receita do produto queijo fatio Fonte: Os Autores, 2020.

O gráfico 5 mostra a receita das vendas de queijo fatio.

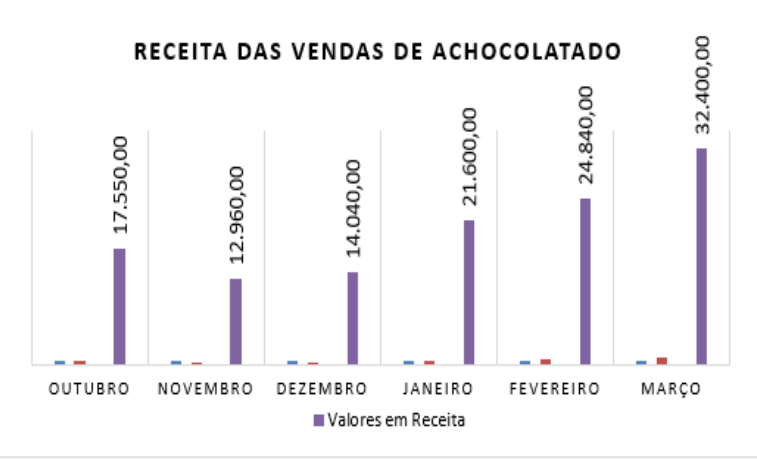

Gráfico 06. Receita do produto achocolatado Fonte: Os Autores, 2020.

O gráfico 5 mostra a receita das vendas de achocolatado.

Dessa forma foi possível identificar a causa raiz da baixa receita dos três produtos mais críticos da empresa, e com isso, foi aplicado o plano de ação através do mapeamento do fluxo de processo, com o intuito de aumentar a receita desses três produtos.

\section{Considerações Finais}

Houve um aumento na receita mensal a partir da implantação das ferramentas de qualidade e gestão na empresa. Além disso, foi realizada a criação de um portfólio para que todos os clientes tivessem o conhecimento da abrangência da empresa e a adoção de comissão para os vendedores desses produtos.

\section{Agradecimentos}

Primeiramente agradeço a Deus, posteriormente a instituição de ensino, juntamente com a orientação e ensinamentos do professor. Aos meus familiares e a empresa que permitiu a análise dos setores do processo de vendas para a implantação das melhorias apontas no artigo.

\section{REFERÊNCIA}

Arbache, F. Gestão de logística, distribuição e trade marketing. 4. ed. Rio de Janeiro: FGV, 2011.

Ballou, R. Gerenciamento da cadeia de suprimentos/ logística empresarial. 5. ed. Porto Alegre: Bookman, 2006.

Behr, A.; Moro, E. L. S.; Estabel, L. B. Gestão da biblioteca escolar: metodologias, enfoques e aplicação de ferramentas de gestão e serviços de biblioteca. Ci. Inf., Brasília, v. 37, n. 2. Disponível em: < http://www.scielo.br/ scielo.php?script=sci_arttext\&pid=S010019652008000200 003\&lng > . Acesso em: 08 de maio de 2020.

Carpinetti, L. C. R. Gestão da qualidade: conceitos e técnicas. 2. ed. São Paulo: Atlas, 2012.

César, Francisco I. Giocondo. Ferramentas básicas da qualidade: Instrumentos para gerenciamento de processos e melhoria contínua. 1. ed. São Paulo: Copyright, 2011.

Daychoum, M. $40+10$ Ferramentas e técnicas de gerenciamento. 5. ed. Rio de Janeiro: Brasport. 2013.

Grosbelli, A. C. Proposta de Melhoria Contínua em um Almoxarifado utilizando a ferramenta 5W2H. 2014. 53 pp. Monografia (Bacharel em Engenharia de Produção) Universidade Tecnológica Federal do Paraná. Medianeira PR, 2014.

Jones, D. T.; Womack, J. P. Enxergando o todo: mapeando o fluxo de valor estendido. São Paulo: Lean Institute Brasil, 2004.

Kume, H. Métodos estatísticos para melhoria da qualidade. 11. ed. São Paulo: Gente, 1993. 245 p.

Meireles, M. Ferramentas Administrativas Para Identificar Observar E Analisar Problemas: Organizações com foco no cliente. Série Excelência Empresarial II. 1. ed. São Paulo: Arte e Ciência, 2001.

Mello, A. E. N. S. Aplicação do mapeamento de processos e da simulação no desenvolvimento de projetos de processos produtivos. 2008. 116 f. Dissertação (Mestrado em Engenharia de Produção) - Universidade Federal de Itajubá, Itajubá 2008. Disponível em< https://www.iepg.unifei.edu.br/arnaldo/download/dissertac oes/Ana\%20Emilia.pdf> Acesso em: 08 de maio de 2020.

Polacinski, A. Implantação dos 5Ss e proposição de um SGQ para uma indústria de erva-mate. 1 ed. São Paulo: Atlas, 2007.

Ramos, A.W. CEP para processos contínuos e em bateladas. São Paulo: Fundação Vanzolini, 2000.

Rother, M.; SHOOK, J. Aprendendo a enxergar: mapeando o fluxo de valor para agregar valor e eliminar desperdícios. São Paulo: Lean Institute Brasil, 2012.

Rother, Mike; Shook, John(2000). Leaming to See, The Lean Enterprise Institute,MA,USA.

Veras, Manoel. 2016. Gestão Dinâmica de Projetos. Rio de Janeiro: Brasport, 2016.

Vieira, S. 1999. Estatística para a qualidade: como avaliar com precisão a qualidade em produtos e serviços. Rio de Janeiro: Campus. 